\title{
Los problemas de reexpresión en la traducción hacia la lengua materna ${ }^{1}$
}

\section{Restructuring problems when translating into the mother tongue}

\author{
Regina Terry Sáenz \\ Universidad Nacional Mayor de San Marcos \\ regina.terry@unmsm.edu.pe \\ oRCID https://orcid.org/oooo-0oo2-4730-7443
}

\begin{abstract}
Resumen
La reexpresión es la etapa en la que se reescribe el texto original en la lengua de llegada. Se trata de una operación textual y un proceso cognitivo que exige del traductor una gran capacidad generativa en su lengua materna. Cualquier desfase operacional entre competencia y actuación o un desarrollo fragmentado de los saberes lingüísticos (elocutivo, idiomático y expresivo) ocasionan problemas durante la reexpresión. El propósito de este estudio es identificar, caracterizar y explicar las causas de los problemas de reexpresión en la traducción que se originan en la lengua materna del alumno de traducción. Las conclusiones que hemos podido extraer señalan que la competencia lingüística del alumno de traducción se encuentra en un estado no finalizado, se observa un desarrollo fragmentado del saber elocutivo, idiomático y expresivo y se revela un desfase operacional entre competencia y actuación.
\end{abstract}

Palabras clave: reexpresión; traducción; competencia lingüística; lengua materna; saberes lingüísticos.

\begin{abstract}
Restructuring means rewriting the source text in the target language. It is both a textual operation and a cognitive process that requires proficient transformational skills in the translator's mother tongue. Any gap between competence and performance or partial access to linguistic knowledge: elocutive, idiomatic, and expressive will cause problems during the restructuring process in Spanish. The present study aims to identify, describe, and explain the causes of restructuring problems in translation resulting from the translator-student's mother tongue. We can conclude that the translator-student's linguistic competence is not fully developed. We can also observe a compartmentalization of linguistic knowledge: elocutive, idiomatic, and expressive, which unveils an operational gap between competence and performance.
\end{abstract}

Keywords: restructuring; translation; language competence; mother tongue; linguistic knowledge.

1 Este artículo se deriva de la investigación de la tesis de maestría en lingüística que se presenta en la Unidad de Posgrado de la Facultad de Letras y Ciencias Humanas de la Universidad Nacional Mayor de San Marcos. 


\section{Resumo}

A re-expressão é a etapa na qual se reescreve o texto original na língua de chegada. Trata-se de uma operação textual é um processo cognitivo que exige do tradutor uma grande capacidade de gerar na sua língua materna. Qualquer defasagem operacional entre a competência e atuação ou um desenvolvimento fragmentado dos saberes linguísticos (elocutivo, idiomático e expressivo) ocasionam problemas durante a re-expressão. O propósito deste estudo é o de identificar, caracterizar e explicar as causas dos problemas de re-expressão na tradução que se originam na língua materna do aluno de tradução. As conclusões que pudemos extrair indicam que a competência linguística do aluno de tradução se encontra em um estado inacabado, observa-se um desenvolvimento fragmentado dos saberes linguísticos: elocutivo, idiomático e expressivo e revela-se uma lacuna operacional entre competência e atuação.

Palavras chaves: re-expressão; tradução; competência linguística; língua materna; saberes linguísticos.

\section{Introducción}

Traducir no es una tarea sencilla. Se trata de una operación textual y un proceso cognitivo que se realiza en tres etapas: (i) la etapa de comprensión, (ii) la etapa de desverbalización y (iii) la etapa de reexpresión. El proceso se inicia cuando el traductor lee el texto original para comprenderlo, luego, extrae el sentido de lo que se quiso decir y, finalmente, reexpresa el mensaje en la lengua de llegada. La capacidad generativa del traductor se pone a prueba durante la reexpresión, ya que debe crear oraciones nunca antes dichas en su lengua sin incumplir las reglas de escritura y transformacionales que los parámetros de la lengua hacia la que traduce le imponen. No obstante, la reexpresión no es un acto de creación discursiva espontánea, pues el texto traducido siempre debe mantener una relación de equivalencia con el original. En ese sentido, García Yebra (1985) afirma que el traductor «tendrá que esforzarse en buscar nuevas posibilidades expresivas acordes con la estructura y la tradición de su propia lengua, que la hagan capaz de manifestar conceptos, sentimientos o matices que percibe en la lengua ajena y que nunca ha visto expresados en la suya» (p. 19). Es así que, durante la reexpresión, el traductor se convierte en un creador de expresiones en la lengua a la que traduce, puesto que traslada el mensaje del texto original con los recursos lingüísticos que le proporciona la lengua de llegada. El éxito o fracaso de dicha operación dependerá de la «maestría comunicativa» (Wotjak, 1986), que el traductor haya alcanzado en su lengua materna. Esta competencia textual implica poseer un amplio repertorio léxico, escoger las unidades léxicas adecuadas según el 
contexto, identificar a los participantes de la situación comunicativa, reconocer las convenciones macroestructurales y microestructurales de los géneros textuales y poseer una gran recursividad estilística (p. 371).

En el caso del alumno de traducción, durante la etapa de reexpresión, él genera oraciones ininteligibles que contravienen los patrones morfosintácticos y semánticos de la lengua española. Llama la atención que, a pesar de traducir hacia su lengua materna, el alumno no aplique su conocimiento intuitivo del español ni detecte este tipo de problemas antes de dar por concluido su proceso de reexpresión. La relevancia de este trabajo estriba en que la mayoría de los estudios en el campo de la traducción se han centrado en tipificar las faltas o errores de traducción que se originan por una comprensión deficiente del texto fuente o por el incumplimiento de la normativa de la lengua hacia la que se traduce. Nosotros nos alejamos de ese enfoque normativo y desde la teoría lingüística, queremos estudiar las razones detrás de los problemas de reexpresión en la traducción que se originan en la lengua materna del alumno de traducción y su relación con la competencia lingüística.

\section{Marco teórico}

Desde el punto de vista de la gramática generativa, existen tres componentes gramaticales: (a) el componente sintáctico, (b) el componente semántico y (c) el componente fonológico. En un sentido amplio, el componente sintáctico nos permite generar secuencias oracionales en una lengua, el componente semántico le otorga un significado a estas secuencias y el componente fonológico hace posible que dichas secuencias sean perceptibles al oído del hablante-oyente ideal. En la reexpresión, el componente sintáctico juega un rol preponderante porque ahí se encuentra almacenada la información que permite generar oraciones gramaticalmente correctas y adecuadas en la lengua hacia la que se traduce. Según Bosque, «es la competencia sintáctica de un individuo lo que le permite producir o reconocer como gramatical o agramatical una secuencia pronunciada por otro hablante» (2009, p. 66). Sin embargo, la evidencia empírica nos demuestra que el alumno de traducción no hace distinción entre las oraciones gramaticales y las agramaticales cuando traduce hacia su lengua materna. Esta incapacidad de reconocer secuencias anómalas podría estar relacionada con el desconocimiento del léxico. Dicho de otro modo, durante la reexpresión, el alumno de traducción se ve forzado a utilizar palabras que no forman parte de su repertorio léxico. Por 
consiguiente, al desconocer la información sintáctica que contiene una unidad léxica y las restricciones que impone a nivel oracional, genera secuencias anómalas al momento de traducir. Al respecto, Fernández Lagunilla y Anula Rebollo (2010, p.8o) sostienen que «el conocimiento del léxico que posee el hablante no es innato (a diferencia de lo que ocurre con el sistema computacional), sino que tiene que ser aprendido». Dicho de otro modo, ser un hablante nativo de español no garantiza que el alumno de traducción aplique las reglas de escritura y las reglas transformacionales del español de manera eficaz. Todo esto nos hace pensar que el desarrollo de la competencia lingüística en L1 del alumno de traducción podría encontrarse en un estado no finalizado. En consecuencia, si queremos contribuir al desarrollo de la competencia lingüística del alumno de traducción, debemos saber cómo está configurada. Según la teoría del hablar, la configuración de la competencia lingüística abarca todo lo que sucede alrededor de la actividad del hablar. Es decir, en la actividad del hablar subyace un conjunto de habilidades y destrezas que funcionan de manera orgánica y articulada. Esta capacidad general de expresión aglutina la capacidad de llevar a cabo todas las actividades extralingüísticas que acompañan a la lengua, la competencia lingüística psicofísica como actividad biológica propia de los seres humanos que se realiza de manera intuitiva e individual y la competencia lingüística cultural que da cuenta del saber lingüístico en sus tres dimensiones: el saber elocutivo (el saber hablar), el saber idiomático (el saber cómo se habla) y el saber expresivo o discursivo (el saber qué hablar). Una precisión importante que hace Coseriu con respecto a la extensión de la competencia lingüística es que «el hablar -prescindiendo también de su determinación extralingüística y psicofísica- es mucho más que la simple realización de una lengua particular» (1992, p. 75), porque no ocurre en un único plano de la lengua, sino que para su realización confluyen, de manera simultánea, un conocimiento universal del hablar en general como facultad humana, un conocimiento de una lengua particular como representación de una comunidad lingüística específica y un conocimiento discursivo que se materializa en un acto de habla concreto. Todo lo señalado hasta el momento refuerza la idea de que podría haber un desarrollo fragmentado de la competencia lingüística en Li del alumno de traducción. Nos interesa, determinar qué planos son los que más problemas generan durante la reexpresión. Para ello, comenzaremos por identificar y caracterizar los problemas que se generan por la información sintáctica y semántica que contiene el léxico para luego explicar las causas que originan los problemas de reexpresión a partir de los saberes lingüísticos. 


\subsection{La caracterización del léxico}

La teoría temática postula que la capacidad generativa de la lengua se encuentra contenida en el léxico y que dichas unidades léxicas no operan unilateralmente, sino que se encuentran sujetas a las restricciones que le imponen los elementos que las anteceden y las suceden. Esto quiere decir que la relación entre el léxico y la sintaxis es indisoluble y que la selección de una unidad léxica determina la distribución sintáctica de todos los ítem léxicos que forman parte de una cadena oracional. Los problemas de reexpresión que se originan en la lengua materna del alumno de traducción revelan que existe un gran desconocimiento de la información sintáctica y de la información semántica que contiene el léxico. Los siguientes rasgos nos han permitido identificar y caracterizar los problemas de reexpresión más frecuentes.

\subsubsection{Los rasgos gramaticales o rasgos - $\varnothing$}

Especifican la persona, el número y el género de los pronombres personales, los sustantivos, los adjetivos y los verbos. Son los rasgos que se toman en cuenta al momento de realizar las flexiones nominales, es decir, cuando se realizan concordancias a nivel sintáctico de género y número, y cuando se aplican en las flexiones verbales que contienen información gramatical como la persona, el tiempo, el aspecto, el caso, entre otros.

\subsubsection{Los rasgos de selección -C (selección categorial)}

Poseen la información sintáctica de las unidades léxicas que primordialmente forman parte del predicado y que es indispensable para configurar oraciones gramaticalmente correctas. El contexto sintáctico determina la categoría de las palabras y de las posibles combinatorias a nivel oracional. Por ejemplo, en «Juan vendió su casa ayer», el verbo «vender» exige un complemento que tenga la categoría de un sn «su casa» y además permite el uso de un adjunto (ayer) por lo que sus rasgos de selección - $C$ podrían describirse de la siguiente manera: vender $\mathrm{sn}+(\mathrm{a})$.

\subsubsection{Los rasgos de selección -S (selección semántica)}

Tienen que ver con las propiedades semánticas que poseen las unidades léxicas. Accedemos a esta información a través de nuestro conocimiento del mundo y es por ello que reconocemos las restricciones de carácter semántico, según el rol que 
dichas unidades léxicas cumplen dentro de la oración. Por ejemplo, el sustantivo «pan» posee como rasgos de selección $-\mathrm{S}[ \pm$ sólido], $[ \pm$ concreto], $[ \pm$ contable]. Por ende, una oración como «bebí el pan» sería incongruente, pues el verbo [beber] va acompañado de sintagmas nominales que poseen el rasgo [+líquido]. La oración gramatical es [comí pan].

\subsubsection{La estructura argumental}

Tiene que ver con la función semántica que cumplen los participantes de un predicado. En [la niña va a la escuela], la función semántica de [la niña] es la de agente, pues es quien realiza la acción. Del mismo modo, el papel semántico de [a la escuela] es el de meta. Por lo tanto, si intentamos describir la estructura argumental del verbo «ir», diríamos que este verbo posee dos argumentos cuyos papeles temáticos son el de agente y el de meta. En la medida que esta red temática se respete, podemos configurar oraciones gramaticalmente correctas.

\subsection{El saber lingüístico}

La extensión de la competencia lingüística cultural abarca tres saberes lingüísticos: un saber elocutivo (un saber hablar), un saber idiomático (un saber cómo se habla) y un saber expresivo (un saber qué hablar). A partir de estos tres saberes, intentaremos descifrar las causas de los problemas de reexpresión que se generan en la lengua materna del alumno de traducción.

\subsubsection{El saber elocutivo}

Es la competencia del hablar en general como actividad humana y social que se rige por los principios del pensamiento humano y el conocimiento enciclopédico. Se basa en el conocimiento que tiene el hablante sobre cómo se habla, lo cual le permite distinguir los enunciados incongruentes y congruentes, identificar los estados de ánimo, saber si está hablando con un adulto o con un niño o si se está hablando con claridad o de manera confusa. Esto quiere decir que el hablante conoce las dos normas que rigen el hablar en general como actividad humana y social, independientemente de cuál sea su lengua particular. La primera norma es la norma de la congruencia que permite distinguir los pensamientos congruentes de los incongruentes. Esta norma se basa en la confianza que el hablante tiene en que su interlocutor siempre diga cosas que tengan sentido, es decir, que sean

338 Lengua y Sociedad. Revista de Lingüística Teórica y Aplicada 
congruentes con el pensamiento humano. La segunda norma es la norma de la tolerancia. Esta norma demuestra la confianza que el hablante tiene en el «saber hablar» de su interlocutor. En el caso del lenguaje figurado, esta norma de tolerancia permite la anulación de la incongruencia que se genera por el uso de metáforas. Gracias a su conocimiento del hablar en general, el hablante reconoce que se trata del lenguaje figurado, anula la incongruencia de la metáfora y la convierte en un enunciado congruente. Esta anulación no solo ocurre en el plano universal, también ocurre en el plano histórico, en la lengua particular, pero estos forman parte del saber idiomático que el hablante posee de su lengua particular; sin embargo, durante la reexpresión el alumno de traducción no anula la incongruencia. En resumen, la competencia lingüística general es el resultado de los procedimientos que se ejecutan a partir del saber elocutivo.

\subsubsection{El saber idiomático}

Es el hablar en una lengua particular, por ejemplo, hablar en español. Su realización exige el empleo de la técnica del hablar que emana de las tradiciones histórico-textuales propias de una comunidad lingüística determinada. Esta «habla repetida» permite que el hablante naif reconozca combinaciones léxicas y sintácticas ya fijadas en su lengua. Al respecto, Coseriu sostiene que «lo específico del habla repetida consiste precisamente en que es un fragmento del hablar que como un todo se inserta en la tradición de la lengua» (1992, p. 281). De esa manera, el hablante reproduce o crea sus propias combinaciones e incluso puede emitir juicios sobre la corrección o incorrección con respecto a los enunciados que escucha, lee o produce. Con respecto a la anulación de la incongruencia, es importante precisar que la tradición lingüística se impone al saber elocutivo, por tanto, el saber idiomático permite anular la incongruencia del hablar en general. Este plano lingüístico también tiene que ver con la designación, es decir, con el significado que se le atribuye a lo designado en las diferentes lenguas particulares, incluso, dentro de una misma lengua. Gracias al conocimiento de la técnica histórica del hablar en una lengua particular, estos significados son comprendidos por los hablantes de una comunidad lingüística determinada. Durante la reexpresión, ese conocimiento resulta fundamental al momento de realizar las combinatorias léxicas y aplicar las reglas distribucionales. En síntesis, la competencia lingüística particular es el resultado de los procedimientos que se ejecutan a partir del saber idiomático. 


\subsubsection{El saber expresivo}

Es el hablar individual y tiene que ver con la competencia textual o discursiva del hablante para producir textos orales o escritos que sean adecuados según la situación comunicativa. Cada acto de habla exige que el hablante haga ajustes en función del interlocutor, el campo, el tenor, el medio y la intención comunicativa. Este conocimiento sociolingüístico permite que el hablante pueda emitir juicios de valor sobre lo que se considera «adecuado» o «inadecuado» en un contexto determinado. El saber expresivo refleja el conocimiento de las reglas que forman parte del hablar en general y de la técnica histórica de la lengua particular que posee el hablante. Durante la reexpresión, el traductor debe hacer gala de una competencia textual altamente desarrollada que le permita producir textos orales y escritos que se adecuen a la situación comunicativa. En conclusión, la competencia textual o discursiva es el resultado de los procedimientos que se ejecutan a partir del saber expresivo.

\section{Metodología}

El estudio que forma parte de este artículo se enmarca en el paradigma descriptivo-explicativo, porque nuestro trabajo de investigación intentó desentrañar los problemas de reexpresión que se originan en la lengua materna del alumno de traducción. Debido a que nuestro objeto de estudio fueron las traducciones hechas por los alumnos de un curso inicial de traducción y nuestro interés era analizar los textos de manera global y no segmentándolos palabra por palabra, decidimos emplear la metodología de la lingüística de corpus, pues nos permite analizar textos completos y no fragmentos u oraciones inconexas (Parodi, 2008, p. 96). Durante un semestre académico, recopilamos el corpus de los textos traducidos del inglés al español y con esa evidencia textual creamos un Corpus de Aprendices de Traducción (САT). Se trabajó con 55 informantes. Todos nuestros informantes eran hablantes nativos del español y tenían un promedio de edad de 20 años. La muestra total está constituida por 108 textos traducidos. Cabe precisar que nuestras unidades de análisis fueron aquellas traducciones en las que se detectaron una mayor cantidad de problemas de reexpresión.

340 Lengua y Sociedad. Revista de Lingüística Teórica y Aplicada 


\subsection{Materiales}

El cat que analizamos contiene 445 entradas. El marco conceptual que empleamos para identificar y caracterizar los problemas de reexpresión más frecuentes corresponde a la Teoría de principios y parámetros, específicamente, en lo que respecta a la caracterización de una entrada léxica y sus propiedades temáticas.

\subsubsection{Matrices de análisis}

Para identificar y caracterizar los problemas de reexpresión que detectamos en el CAT, utilizamos el modelo de caracterización del léxico propuesto por la teoría temática y para determinar los orígenes de los problemas de reexpresión en la lengua materna del alumno de traducción, utilizamos el modelo de configuración de la competencia lingüística desarrollado en la Teoría del hablar. Al cruzar estas dos matrices, pudimos identificar los problemas de reexpresión más frecuentes que se originan en la lengua materna del alumno de traducción y determinar su vínculo con la competencia lingüística.

\subsubsection{Matriz de análisis para la identificación y caracterización de los problemas de reexpresión}

\begin{tabular}{l|l}
\hline Tipo de problema & Definición \\
\hline $\begin{array}{l}\text { Problemas relacionados con los } \\
\text { rasgos de selección }-S \text { (selección } \\
\text { semántica) }\end{array}$ & $\begin{array}{l}\text { Tienen que ver con las propiedades semánticas } \\
{[ \pm \text { animado], }[ \pm \text { concreto], }[ \pm \text { contable], }[ \pm} \\
\text { humano] que son inherentes a cada unidad } \\
\text { léxica. }\end{array}$ \\
\hline $\begin{array}{l}\text { Problemas relacionados con los } \\
\text { rasgos de selección }-\mathrm{C} \text { (selección } \\
\text { categorial) }\end{array}$ & $\begin{array}{l}\text { Tienen que ver con la información sintáctica } \\
\text { que contiene el léxico y que determina el tipo } \\
\text { de categoría que deben respetar los objetos } \\
\text { seleccionados dentro de la oración. }\end{array}$ \\
\hline $\begin{array}{l}\text { Problemas relacionados con los } \\
\text { rasgos gramaticales o rasgos }-\varnothing\end{array}$ & $\begin{array}{l}\text { Especifican los rasgos de concordancia tales } \\
\text { como la persona, el número y el género de las } \\
\text { categorías léxicas y funcionales. }\end{array}$ \\
\hline $\begin{array}{l}\text { Problemas con la estructura } \\
\text { argumental }\end{array}$ & $\begin{array}{l}\text { Tienen que ver con el número de argumentos y el } \\
\text { tipo de papeles temáticos que un predicado exige } \\
\text { en función de su significado. }\end{array}$ \\
\hline
\end{tabular}

Nota. Elaboración propia 
Los problemas de reexpresión en la traducción hacia la lengua materna

Regina Terry Sáenz

\subsubsection{Matriz de análisis para la explicación de los orígenes de los problemas de reexpresión}

\begin{tabular}{|c|c|c|}
\hline \multicolumn{3}{|c|}{ Configuración de la competencia lingüística } \\
\hline $\begin{array}{l}\text { Saber } \\
\text { lingüístico }\end{array}$ & Definición & Alcances de la competencia \\
\hline $\begin{array}{l}\text { Saber } \\
\text { elocutivo }\end{array}$ & $\begin{array}{l}\text { Es la competencia del hablar } \\
\text { en general como actividad } \\
\text { humana y social que se } \\
\text { rige por los principios del } \\
\text { pensamiento lógico y el } \\
\text { conocimiento enciclopédico. }\end{array}$ & $\begin{array}{l}\text { Permite reconocer enunciados } \\
\text { incongruentes/congruentes, } \\
\text { identificar estados de ánimo, saber si } \\
\text { está hablando un adulto o un niño o } \\
\text { si se está hablando con claridad o no. }\end{array}$ \\
\hline $\begin{array}{l}\text { Saber } \\
\text { idiomático }\end{array}$ & $\begin{array}{l}\text { Es la capacidad de hablar en } \\
\text { una lengua particular gracias } \\
\text { a una técnica histórica del } \\
\text { hablar que forma parte de } \\
\text { una comunidad lingüística } \\
\text { específica. }\end{array}$ & $\begin{array}{l}\text { Permite reconocer las tradiciones } \\
\text { del hablar de la lengua particular } \\
\text { así como sus tradiciones textuales y } \\
\text { se pone de manifiesto la condición } \\
\text { de hablante naif para emitir juicios } \\
\text { sobre corrección/incorrección o }\end{array}$ \\
\hline $\begin{array}{l}\text { Saber } \\
\text { expresivo }\end{array}$ & $\begin{array}{l}\text { La capacidad de cada } \\
\text { individuo para producir } \\
\text { textos (orales y escritos) en } \\
\text { situaciones particulares. }\end{array}$ & $\begin{array}{l}\text { Permite expresarse de manera } \\
\text { adecuada según la situación } \\
\text { comunicativa en la que se encuentra } \\
\text { y configurar los textos según el } \\
\text { medio, registro, contexto, campo, } \\
\text { tono, etc. }\end{array}$ \\
\hline
\end{tabular}

Nota. Elaboración propia

\section{Análisis}

De las 445 entradas analizadas, 223 revelan problemas relacionados con los rasgos de selección semántica, 175 están vinculados con los rasgos de selección categorial, 32 tienen que ver con la estructura argumental y 15 guardan relación con los rasgos gramaticales.

\subsection{Problemas con los rasgos de selección -S.}

Entre los 223 problemas de rasgos de selección semántica, identificamos (i) problemas con los rasgos semánticos, (ii) problemas con las combinatorias fijas, (iii) problemas con la variedad diafásica y (iv) problemas de comprensión del texto en inglés. 


\subsubsection{Problemas con los rasgos semánticos}

(1)

[An article from TIME magazine declared...]

[Un artículo de la revista time declaró...]

El verbo «declarar» va acompañado de sintagmas nominales que poseen el rasgo [+ humano]. El sustantivo «artículo» no posee ese rasgo. La oración debió ser «En un artículo de la revista TIME, se señalaba que [...]».

\subsubsection{Problemas con las combinatorias fijas}

(2)

[We are in a deep mess]

[Estamos sumergidos en un gran problema]

La combinatoria estable de verbos que acompañan al sustantivo «problema» es «enfrascar, meter»y no «sumergirse». La oración debió ser «Estamos enfrascados en un gran problema».

\subsubsection{Problemas con la variedad diafásica}

(3)

[... to either sell or spin off its TikTok business in the Us.]

[... para vender o dejar el negocio de TikTok en los EE. UU]

El verbo «dejar» significa «retirarse o apartarse de algo o de alguien» y la colocación «dejar el negocio» no corresponde a «spin off its business» que es una expresión del campo económico que hace referencia a «la división o partición de una empresa con el fin de crear una nueva». La oración debió ser «[...] para vender o escindir su negocio de TikTok en los EE.UU». 


\subsubsection{Problemas de comprensión del texto en inglés}

(4)

[a 205 per cent year-on-year increase in policies for cats]

[un aumento interanual del 205 por ciento en reglamentos para la protección de los gatos]

El sustantivo «reglamento» se refiere a «una colección ordenada de reglas o preceptos» y no corresponde al término en inglés "policies» que en este contexto hace referencia a «un documento justificativo del contrato de seguros ». La oración debió ser « [...] incremento en las pólizas de seguro para gatos».

\subsection{Problemas con los rasgos de selección -C}

Entre los 175 problemas de rasgos de selección categorial, detectamos problemas relacionados con (i) los complementos de régimen, (ii) las propiedades sintácticas del verbo, (iii) los constituyentes de los sintagmas y (iv) las estructura interna de la oración compuesta.

\subsubsection{Problemas con los complementos de régimen}

(5)

[... to pass judgment in such a delicate matter]

[...para dar juicio en un problema tan delicado]

El sustantivo «juicio» exige un complemento de régimen introducido por la preposición «sobre» y no «en». La oración debió ser «[...] para emitir un juicio sobre un tema tan delicado».

\subsubsection{Problemas con las propiedades sintácticas del verbo}

(6)

[consult their social networks]

[consultan a sus redes sociales]

El verbo «consultar» cuando significa «examinar» exige un complemento directo no indirecto. La oración debió ser «[...] consultan sus redes sociales [...]». 


\subsubsection{Problemas con los constituyentes de los sintagmas}

(7)

[the to-do list is the answer to all your productivity problems

[La lista de qué hacer es la respuesta a todos tus problemas de productividad]

La configuración de un sintagma preposicional exige que su núcleo esté constituido por un sustantivo. La oración debió ser «la lista de quehaceres».

\subsubsection{Problemas con la estructura interna de la oración compuesta}

(8)

[Dr. Lillian Glass, a California-based communication and psychology expert who says she coined the term in her 1995 book Toxic People ...]

[Lillian Glass, una psicóloga experta en comunicación situada en California que dice que acuñó el término en su libro Toxic People publicado en 1995...]

Después de la aposición se debió utilizar una cláusula relativa seguida de una oración compuesta coordinada. La oración debió ser «Lilian Glass, psicóloga experta, quien radica en California y acuñó el término en su libro Toxic People publicado en $1995[\ldots] »$.

Por otro lado, los problemas menos frecuentes son los que tienen que ver con la estructura argumental y los rasgos gramaticales. De un total de 445 entradas analizadas, 32 están relacionadas con la estructura argumental y 15 son problemas vinculados a los rasgos gramaticales.

\subsection{Problemas con la estructura argumental}

(9)

[it would be irresponsible to neglect them]

[sería irresponsable descuidarlas] 
Para evitar la ambigüedad gramatical, se exige la presencia del agente. La oración debió ser «Yo sería irresponsable si las descuido».

\subsection{Problemas con los rasgos gramaticales}

(10)

[... the kind of person who is open to advice]

[... el tipo de persona que está dispuesto a recibir consejos]

No hay concordancia entre el sintagma nominal y su complemento predicativo. La oración debió ser « [...] el tipo de persona que está dispuesta a recibir consejos $[\ldots] »$.

\section{Interpretación de los resultados}

El corpus analizado nos ha permitido identificar y caracterizar los problemas de reexpresión más frecuentes. Es así que hemos podido determinar qué relación guardan los problemas de reexpresión con la competencia lingüística. Para empezar, algunos de los problemas con los rasgos semánticos tendrían su origen en el saber elocutivo, pues este estudio encontró que el alumno de traducción no aplica la norma de congruencia durante la etapa de reexpresión. Dicho de otro modo, si realmente lo hiciera, ese «saber hablar» le permitiría reconocer y anular la incongruencia en las traducciones que hace del inglés hacia su lengua materna.

(11)

[... Twitter was possibly interested]

[... es posible que Twitter esté interesado]

El adjetivo «interesado» va acompañado de sintagmas nominales que poseen el rasgo [+humano] y el nombre propio «Twitter» no posee ese rasgo. La oración debió ser «[...] los dueños de Twitter están interesados [...]».

Del mismo modo, otros problemas con los rasgos semánticos tendrían su origen en el saber idiomático, pues los resultados nos muestran que el alumno de traducción, aparentemente, desconoce la técnica del hablar que, como hablante nativo del español, debería ser parte de su conocimiento intuitivo. Si aplicase dicho conocimiento, este «saber cómo se habla» le permitiría utilizar las combinatorias 
estables del español y reconocer las restricciones sistemáticas de las combinatorias que intenta generar durante la reexpresión.

(12)

[... the power of social media. It's immense ...]

[...las redes sociales tienen un alcance inmensurable..]

La combinatoria estable de adjetivos que acompañan el sustantivo «alcance» es «amplio, considerable, extenso, ilimitado, vasto» no «inmensurable». La oración debió ser «[...] tienen un alcance extenso [...]».

(13)

[With our new culture of masking ...]

[Con esta nueva cultura de enmascaramiento ...]

Al realizarse el proceso de nominalización del verbo «enmascarar» al sustantivo «enmascaramiento», el sentido que se le atribuye es el de «situaciones encubiertas o disimuladas» y no corresponde al término en inglés «masking» que describe «un objeto que cubre la cara o parte de ella para protegerla u ocultarla». La oración debió ser «[...] con esta nueva costumbre de usar máscaras [...]».

Igualmente, los problemas asociados a la variedad diafásica tendrían su origen en el saber expresivo. Según Coseriu, «Éste sólo se consigue poco a poco y prácticamente nunca para todos los tipos de texto. La formación en este saber es objeto de una educación lingüística, en la que se facilita la manera de construir o crear textos» (1992, p. 249). El alumno de traducción no adecua el léxico ni la sintaxis a la situación comunicativa del texto en inglés. Si desarrolla este "saber qué hablar» según la situación comunicativa, el alumno de traducción podrá identificar el tenor, el medio, el campo y la función comunicativa antes de seleccionar una palabra o una construcción sintáctica en la etapa de reexpresión.

(14)

[I have Cloudg to help me with that though, it's just chill, it's not anything. I can't handle]

[Sin embargo, tengo Clouds para ayudar con eso, es simplemente relajado. No es algo que no pueda manejar] 
En este enunciado hay varias expresiones coloquiales en inglés que pertenecen a la lengua oral tales como «Cloud 9, though, just chill, can’t handle». Se debió optar por expresiones en español que mantuvieran el tenor informal y la expresividad del medio oral. La oración debió ser «Pero para eso fumo mis porritos, porque me ayudan a relajarme, así que no pasa nada [...]».

Asimismo, los problemas de selección -S relacionados con la comprensión del texto en inglés tendrían su origen en un desarrollo incompleto de la competencia lingüística en L2. El alumno de traducción no reconoce expresiones idiomáticas, ni las propiedades léxicas de las palabras. Tampoco distingue los tiempos absolutos de los tiempos relativos ni logra identificar las relaciones lógicas explícitas o implícitas que se establecen a lo largo del texto, tal como se observa en los siguientes ejemplos:

$(15)$
[I'm just riding this train]
[solo estoy viajando en este tren]

La expresión «I’m just riding the train» se utiliza para referirse a situaciones temporales que generan placer. La oración debió ser «[...] solo la estoy pasando bien».

(16)

[your collie is now your colleague]

[Tu perro ahora es tu compañero]

El hiperónimo «compañero» se refiere a «una persona que se acompaña con otra para algún fin» y no corresponde al hipónimo en inglés «colleague», que es un término específico para referirse a «una persona que trabaja en una organización». La oración debió ser «Tu perro es ahora tu compañero de trabajo».

$(17)$

[I have been an immigration judge for more than 11 years ... ]

[He sido juez de inmigración por mas de 11 años...]

El pretérito perfecto compuesto no corresponde al tiempo verbal en inglés «have been», pues se expresa una coincidencia temporal entre el hecho referido y el momento de hablar, y el verbo hace referencia a un tramo temporal de cierta

348 Lengua y Sociedad. Revista de Lingüística Teórica y Aplicada 
duración. Se debió utilizar el presente de indicativo. La oración debió ser « [...] Soy juez de inmigración desde hace más de 11 años [...]»

(18)

[Let's talk about procrastination! But first, I heard the washing machine beep that it's finished ...]

[;Hablemos de la procrastinación! Pero primero, escuché el pitido de la lavadora, eso significa que ha terminado ...]

En este contexto «but» funciona como un conector discursivo disgresivo y no como una conjunción adversativa. La oración debió ser «iHablemos de la procrastinación! Por cierto, acaba de sonar la lavadora [...]».

Por otro lado, el origen de los problemas de selección-C, se encontraría en el desconocimiento del léxico en español. Esto significa que el alumno de traducción desconoce las restricciones distribucionales a nivel morfosintáctico y, por tanto, genera oraciones agramaticales o construcciones anómalas durante la etapa de reexpresión. Del mismo modo, un bilingüismo subordinado sería el responsable de las transferencias negativas que ocasionan problemas con los rasgos de selección categorial durante la reexpresión, tal como se evidencia en los siguientes ejemplos:

(19)

[Try something new]

[Prueba con algo nuevo]

El verbo «probar» en el sentido de «hacer prueba, experimentar o intentar algo» es intransitivo y exige la preposición «a». La oración debió ser «Pruebe a hacer algo nuevo».

(20)

[...don't create a giant inventory of random, and perhaps unimportant, tasks...

[...no crees un inventario gigantesco al azar, y quizás insignificante, de tareas...]

Se ha producido una transferencia negativa del orden de los constituyentes del sintagma nominal complejo en inglés $[(s a+s n)+(s p+c o n j+a+s a+s n)]$. En español la configuración de este sintagma nominal complejo es [sn+(sa+sp+a+osr)]. La 
oración debió ser: «[...] no crees un inventario gigantesco de tareas al azar que no son importantes».

En lo que respecta a los problemas con la estructura argumental, estos tendrían su origen en la competencia lingüística en L1 y L2, es decir, en un bilingüismo subordinado, el cual sería el responsable del calco de las valencias verbales del inglés al español.

(21)

[The same goes for pets]

[Lo mismo va para las mascotas]

El predicado en español exige dos argumentos: el agente y el paciente. La oración debió ser «Deberías hacer lo mismo con las mascotas [...]».

Finalmente, el origen de los problemas de rasgos gramaticales se encontraría en el saber expresivo, es decir, en la capacidad de producir textos escritos en la lengua materna. Como integrante de la generación $\mathrm{Z}$, el alumno de traducción, es primordialmente un usuario de la lengua oral. Por consiguiente, durante la reexpresión, tiende a reproducir los rasgos de la oralidad. Una de estas características es la sintaxis desmembrada que forma parte del habla espontánea y que no exige el cumplimiento riguroso de la concordancia gramatical.

(22)

[And these relationships don't have to be ...]

[Además, este tipo de relaciones no tienen que ser ...]

El sintagma nominal y el sintagma verbal tiene que concordar en número. La oración debió ser «[...] este tipo de relaciones no tiene que ser [...]».

\section{Conclusiones}

Es razonable concluir, a partir del análisis de los datos, que las oraciones con problemas relacionados a los rasgos de selección semántica infringen el principio de aceptabilidad y, por tanto, revelan un desfase operacional a nivel de la actuación lingüística del alumno de traducción, mientras que las oraciones con problemas asociados a los rasgos de selección categorial, infringen el principio de gramaticalidad, lo que significa que su competencia estaría en un estado no finalizado. Este desarrollo fragmentado de la competencia y el desfase operacional de 
la actuación lingüística cobra mayor importancia en la traducción, ya que traducir es una actividad creativa que pone a prueba la capacidad generativa del alumno de traducción, quien debe utilizar la información almacenada en su diccionario mental para poder aplicar las reglas de reescritura y las reglas de transformación durante la reexpresión.

Tomados en conjunto, estos resultados sugieren que el origen de los problemas de reexpresión en la lengua materna se desencadena en uno (o varios) de los planos que configuran la competencia lingüística. Hemos sido capaces de extraer esta conclusión porque la evidencia empírica nos demuestra que, durante la reexpresión, el alumno de traducción (i) ignora las normas que rigen el saber elocutivo y genera enunciados incongruentes, (ii) no emplea la técnica del hablar ni apela a su conocimiento intuitivo para generar enunciados idiomáticos y (iii) no sigue los procedimientos para la formación de textos ni las convenciones propias de la lengua escrita.

Por último, los cursos de lengua materna para traductores deberían concentrar sus esfuerzos en fomentar el enriquecimiento del léxico y el desarrollo de la capacidad generativa del alumno de traducción, mediante ejercicios que pongan a prueba su conocimiento de las reglas de escritura y de las reglas de transformación. Para lograr este propósito, la metodología de la lingüística de corpus resulta de suma utilidad, ya que permite el análisis de textos auténticos que reflejan el uso real de la lengua a través del léxico y la sintaxis. Además, se debería implementar una política lingüística que ponga en relieve la importancia de la lengua materna, pues constituye la piedra angular de la actividad traductora. Esta política lingüística debería promover la cultivación y enriquecimiento de la lengua materna del alumno de traducción a lo largo de los cinco años de formación profesional. Finalmente, entre las futuras y posibles preguntas de investigación que pueden formularse a partir de los resultados obtenidos en esta investigación se encuentran el poder determinar si un análisis más profundo del perfil sociolingüístico del alumno de traducción podría revelar otras causas que expliquen el desarrollo no finalizado de la competencia lingüística en L1. Sería interesante, por ejemplo, averiguar si se trata de un caso particular de estos jóvenes limeños o si, por el contrario, se trata de una característica lingüística de los jóvenes de la Generación Z. 


\section{Agradecimientos}

Estoy especialmente agradecida al Dr. Manuel Conde, profesor principal del Departamento de Lingüística en la Universidad Nacional Mayor de San Marcos por sus valiosos comentarios y opiniones sobre este trabajo de investigación.

Financiamiento

La investigación se realizó sin financiamiento.

\section{Conflicto de intereses}

La autora no posee ningún conflicto de intereses.

\section{Referencias bibliográficas}

Bosque, I. (2015). Las categorías gramaticales. Relaciones y diferencias. Editorial Síntesis,

S.A.

Bosque, I. (2019). Repaso de sintaxis tradicional: Ejercicios de autocomprobación. Arco/Libros-La Muralla, S. L.

Bosque, I. y Gutiérrez-Rexach, J. (2009). Fundamentos de sintaxis formal. Ediciones Akal, S. A.

Bosque, I. (2006) Diccionario combinatorio del español contemporáneo. REDES. Ediciones SM.

Chomsky, N. (2015). Aspects of the Theory of Syntax. 5oth Anniversary Edition. Massachusetts Institute of Technology. (c) 1965 Massachusetts Institute of Technology.

Chomsky, N. (2017). The Architecture of Language. Oxford University Press. Universidad de Granada.

Conde Marcos, M. (2017). La teoría temática: fundamentos y propuesta restrictiva. Lengua y

Sociedad, 13(1), 99-118. http://revista.letras.unmsm.edu.pe/index.php/ls/article/ view/443

Coseriu, E. (2002). Competencia Lingüística. Elementos de la teoría del hablar. Gredos.

Coseriu, E. (2007). Lingüística del texto. Introducción a la hermenéutica del texto. Arco Libros.

Coseriu, E. (2016). La semántica en la lingüística del siglo Xx: tendencias y escuelas. Arco Libros. 
Fernández Lagunilla, M. y Anula Rebollo, A. (2010). Sintaxis y Cognición. Introducción a la gramática generativa. Editorial Síntesis. S.A.

García Yebra, V. (1984 a). Teoría y práctica de la traducción I. Manuales. Biblioteca Románica Hispánica. Editorial Gredos.

García Yebra, Valentín. (1984 b). Teoría y práctica de la traducción II. Manuales. Biblioteca Románica Hispánica. Editorial Gredos.

García Yebra, Valentín. (1985). Traducción y Enriquecimiento de la lengua del traductor. Real Academia de la lengua española.

Hurtado Albir, A. (2019). Traducción y traductología. Introducción a la traductología. Ediciones Cátedra.

Moreno Fernández, Francisco. (2008). Principios de sociolingüística y sociología del lenguaje. Ariel Letras.

Parodi, G. (2008). Lingüística de Corpus: Una Introducción al Ámbito. RLA. Revista de Lingüística Teórica y Aplicada, 46 (1), 93-119. https://dx.doi.org/10.4067/ So718-48832008000100006

Real Academia Española y Asociación de Academias de la Lengua Española. (2005). Diccionario Panhispánico de dudas. Santillana.

Real Academia Española. (2008). Corpus de referencia del español actual CREA (22.a ed.). https://corpus.rae.es/creanet.html

Real Academia Española. (2014). Diccionario de la lengua española (23.a ed.). http://www.rae.es/rae.html

Real Academia Española y Asociación de Academias de la Lengua Española. (2019). Glosario de términos gramaticales. Ediciones Universidad de Salamanca.

Wotjak, G. (1986). Acerca de la adecuación de la traducción al receptor. Revista De Filología Románica, (4), 369. https://revistas.ucm.es/index.php/RFRM/article/ view/RFRM8686110369A

Wotjak, G. (2006). Las lenguas, ventanas que dan al mundo. El léxico como encrucijada entre morfosintaxis y cognición: aspectos semánticos y pragmáticos en perspectiva intra e interlingüística. Editorial: Universidad de Salamanca.

Zagona, K. (2006). Sintaxis generativa del español. Visor Libros. S.L. 


\section{Anexo}

\section{Unidades de análisis referenciadas en el presente artículo}

(1)

[An article from TIME magazine declared: «They have trouble making decisions»]

[Un artículo de la revista TIME declaró: «Tienen problemas para tomar decisiones»]

(2)

[We are in a deep mess: there is no simple «democratic» solution here] [Estamos sumergidos en un gran problema: No hay una simple solución democrática]

(3)

[On Friday, President Trump issued an executive order giving ByteDance 90 days to either sell or spin off its TikTok business in the us]

[El viernes, el presidente Trump emitió una orden ejecutiva y le da 9o días a ByteDance para vender o dejar el negocio de TikTok en los EE. UU]

(4)

[By May, it was reported that the nation was in the grip of a puppy shortage, and in July, insurers Bought By Many reported a 205 per cent year-on-year increase in policies for cats]

[En mayo, se informó que la nación estaba sufriendo una escasez de cachorros y, en julio, las aseguradoras de Bought By Many informaron sobre un aumento interanual del 205 por ciento en reglamentos para la protección de los gatos]

(5)

[Even if their comprehension is not distorted by corporate interests, what qualifies them to pass judgement in such a delicate matter?]

[Incluso si su capacidad de comprensión no estuviera distorsionada por intereses empresariales ¿Qué los califica como personas aptas para dar juicio en un problema tan delicado?] 
(6)

[Did you know that before they make a purchase, $86 \%$ of women consult their social networks, and $40 \%$ of Twitter users have bought an item based purely on a tweet?]

[¿Sabías que, antes de que hagan una compra,86\% de mujeres consultan a sus redes sociales, y que el $40 \%$ de los usuarios de Twitter han comprado un artículo basándose solamente en un tuit?]

(7)

[In theory, the to-do list is the answer to all your productivity problems]

[En teoría, la lista de qué hacer es la respuesta a todos tus problemas de productividad]

(8)

[Dr. Lillian Glass, a California-based communication and psychology expert who says she coined the term in her 1995 book Toxic People, defines a toxic relationship as «any relationship [between people who] don't support each other, where there's conflict and one seeks to undermine the other, where there's competition, where there's disrespect and a lack of cohesiveness.»]

[Lillian Glass, una psicóloga experta en comunicación situada en California que dice que acuñó el término en su libro Toxic People publicado en 1995, define una relación tóxica como «cualquier relación (entre personas que) no se apoyan mutuamente, donde existe el conflicto y uno busca minimizar al otro, donde existe competencia, donde no existe el respeto y la unión de pareja»]

(9)

[And my plants need watering - it would be irresponsible to neglect them. And, before I forget, I need to look up that thing that someone told me about]

[Y mis plantas necesitan ser regadas, sería irresponsable descuidarlas. $Y$, antes de que se me olvide, necesito buscar eso que alguien me dijo] 
(10)

[If you are the kind of person who is open to advice, find a friend to have a moan with]

[Si eres el tipo de persona que está dispuesto a recibir consejos, búscate un amigo con quien quejarte]

(11)

[Microsoft has been in talks to acquire TikTok - a deal which co-founder Bill Gates called a «poisoned chalice» - and reports last week suggested Twitter was possibly interested]

[Microsoft ha estado conversando para adquirir TikTok, un acuerdo que el cofundador Bill Gates llamó" cáliz envenenado", y los informes del mes pasado sugirieron que es posible que Twitter este interesado]

(12)

[This has made many businesses active on social media in efforts to build a favorable presence, as social media has an unquantifiable reach]

[Esto ha hecho que varias empresas estén activas en redes sociales para construir una imagen favorable, ya que estas redes tienen un alcance inmensurable]

(13)

[With our new culture of masking, we now smile through the eyes as we march on giving us the option to see the world through its eye whilst seeking the human soul through our masked beings]

[Con nuestra nueva cultura de enmascaramiento, sonreímos a través de los ojos mientras continuamos dándonos la opción de ver el mundo a través de sus ojos mientras ve el alma humana a través de nuestros seres enmascarados]

(14)

[It kind of happened so quick. I have Cloudg to help with that though, it's just chill. It's not anything I can't handle]

[Sucedió tan rápido. Sin embargo, tengo Cloudg para ayudar con eso, es simplemente relajado. No es algo que no pueda manejar] 
(15)

[I'm just riding this train and enjoying it]

[solo estoy viajando en este tren y disfrutándolo]

(16)

[Your computer is now your work computer. Your children are now your colleagues. Your collie is now your colleague. We must not let standards drop! We must work harder!]

[Tu computadora ahora es tu nueva computadora de trabajo. Tus hijos ahora son tus compañeros de trabajo. Tu perro ahora es tu compañero. ¡No debemos dejar caer los estándares! ¡Debemos trabajar más duro!]

(17)

[I have been an immigration judge for more than 11 years, and nobody has ever tried to influence a single one of my thousands of decisions]

[En realidad, he sido juez de inmigración por mas de 11 años y nunca nadie ha tratado de influir en una sola de mis miles de decisiones]

(18)

[Let's talk about procrastination! But first, I heard the washing machine beep that it's finished so I'm just going to take care of that laundry]

[¡Hablemos de la procrastinación! Pero primero, escuché el pitido de la lavadora, eso significa que (159) ha terminado, así que (160) me voy a encargar de esa ropa]

(19)

[Exercise won't cure your stress, but it can help to clear your head and make you feel as if you're gaining some control. Try something new: yoga may be calming, but there's nothing more thrilling than pummelling a punchbag]

[El ejercicio no curará su estrés, pero puede ayudar a aclarar su mente $y$ hacer que se sienta como si estuviera obteniendo algo de control. Prueba con algo nuevo. El yoga puede ser relajante, pero no hay nada más emocionante que golpear un saco de boxeo] 
(20)

[To create an effective action list, fill it with things on which you will truly take action; don't create a giant inventory of random, and perhaps unimportant, tasks]

[Para crear una lista de acción efectiva, llénala con cosas de las que de verdad te harás cargo; no crees un inventario gigantesco al azar, y quizás insignificante, de tareas]

$(21)$

[If you would not bring your children to the office, then find somewhere else for them to stay. The same goes for pets. One thing for sure: They should not appear on your conference calls]

[Si no llevarías a tus hijos a la oficina, entonces encuentra cualquier otro lugar para que se queden. Lo mismo va para las mascotas. Una cosa es segura: ellos no deberían aparecer en tus video conferencias]

(22)

[And these relationships don't have to be romantic: Glass says friendly, familial and professional relationships can all be toxic as well]

[Además, este tipo de relaciones no tienen que ser románticas: Lillian Glass dice que las relaciones amicales, familiares y profesionales también pueden ser tóxicas]

\section{Trayectoria académica de la autora}

Regina Terry es tesista de la Maestría en Lingüística de la Universidad Nacional Mayor de San Marcos. Es Licenciada en Traducción e Interpretación por la Universidad Ricardo Palma y egresada de la facultad de Educación de la Pontificia Universidad Católica del Perú. Posee una segunda especialidad en Enseñanza de Inglés como Lengua Extranjera de la PUCP y un Diplomado en Gestión de Programas de Enseñanza de Idiomas de la Universidad de Baltimore en los EE.UU. Su campo de investigación gira en torno a la lingüística contrastiva, la traductología y la semántica cognitiva.

358 Lengua y Sociedad. Revista de Lingüística Teórica y Aplicada 